\title{
Correction
}

\section{Correction to: Inhibition of p53 and/or AKT as a new therapeutic approach specifically targeting ALT cancers}

\author{
Yuanlong $\mathrm{Ge}^{1,2}$, Shu $\mathrm{Wu}^{1,2}$, Zepeng Zhang ${ }^{1,2}$, Xiaocui $\mathrm{Li}^{1,2}$, Feng $\mathrm{Li}^{1}$, Siyu Yan ${ }^{1}$, Haiying Liu ${ }^{1,2}$, \\ Junjiu Huang', Yong Zhao ${ }^{1,2 \bowtie}$
}

${ }^{1}$ MOE Key Laboratory of Gene Function and Regulation, State Key Laboratory of Biocontrol, School of Life Sciences, Sun Yatsen University, Guangzhou 510006, China

${ }^{2}$ Collaborative Innovation Center of High Performance Computing, National University of Defense Technology, Changsha 410073, China

$\bowtie$ Correspondence: zhaoy82@mail.sysu.edu.cn (Y. Zhao)

\section{CORRECTION TO: PROTEIN CELL HTTPS:/IDOI. ORG/10.1007/S13238-019-0634-Z}

In the original publication the labels in Fig. 4C and 4D are incorrectly published. The correct labels for Fig. $4 \mathrm{C}$ and $4 \mathrm{D}$ is provided in this correction.

\section{OPEN ACCESS}

This article is distributed under the terms of the Creative Commons Attribution 4.0 International License (http://creativecommons.org/ licenses/by/4.0/), which permits unrestricted use, distribution, and reproduction in any medium, provided you give appropriate credit to the original author(s) and the source, provide a link to the Creative Commons license, and indicate if changes were made.

Yuanlong Ge and Shu Wu have contributed equally to this work.

The original article can be found online at https://doi.org/10.1007/ s13238-019-0634-z. 
A
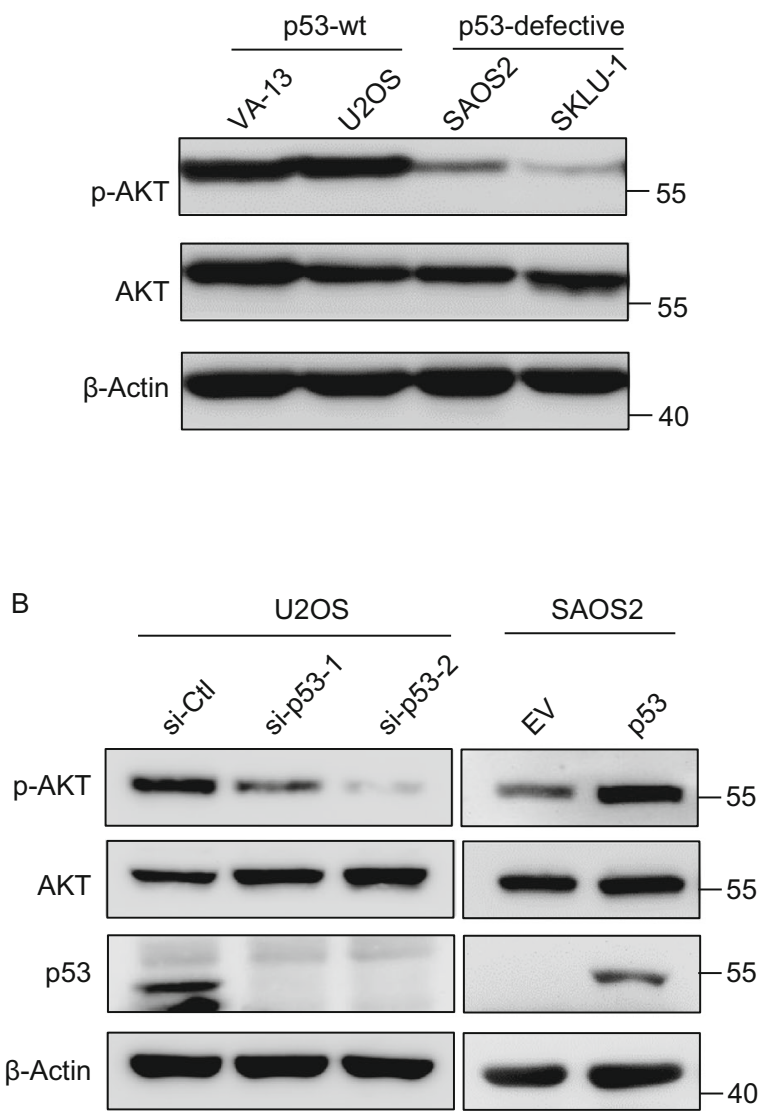

C

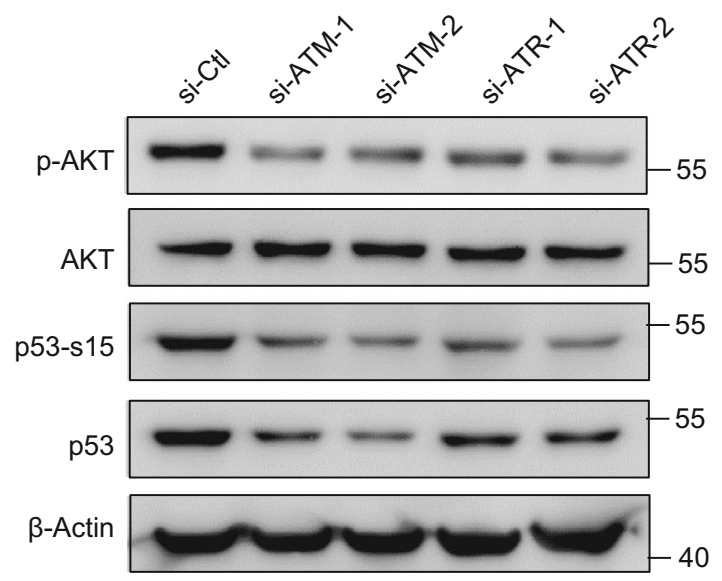

D
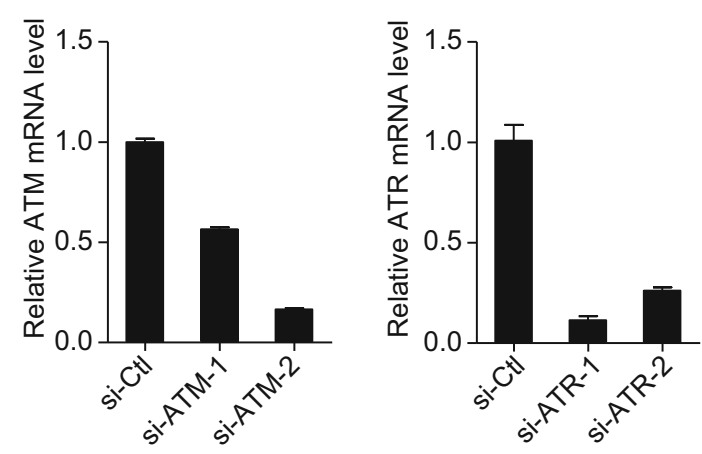

E

$$
\begin{array}{llllll}
\multicolumn{2}{c}{\text { KU60019 }} & & \multicolumn{2}{c}{\text { VE-821 }} \\
0 & 5 & 10 & 0 & 5 & 10 \mu \mathrm{mol} / \mathrm{L}
\end{array}
$$

p-AKT
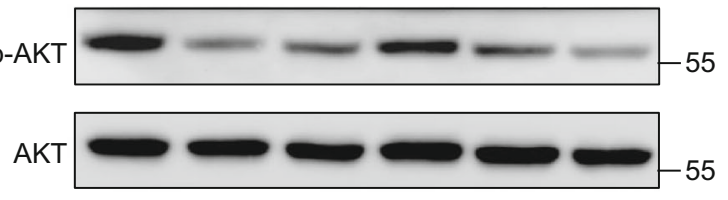

$\beta$-Actin

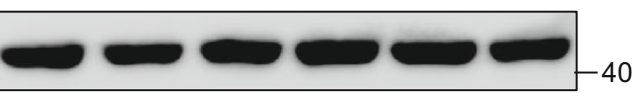

F

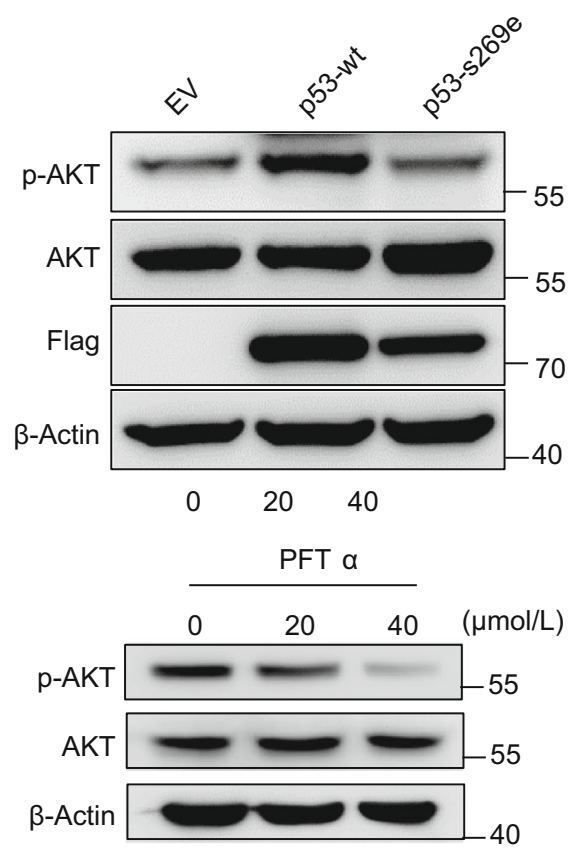

Figure 4. AKT is phosphorylated in p53-dependent manner in ALT cells. (A) Western blot determination of total and phosphorylated AKT (S473) in p53-positive (VA13, U2OS) and p53-defective (SAOS2, SKLU-1) ALT cells. (B) Knockdown of p53 in U2OS or moderate expression of p53 in SAOS2 induces down or up-regulation of p-AKT, respectively. (C) Knockdown of ATM or ATR by siRNA decreases abundance of p53, phosphorylated p53 and p-AKT. (D) Quantitative-PCR determination of the level of ATR or ATM in U2OS cells transfected with siRNA to ATR or ATM, respectively. Scramble siRNA (Si-Ctl) was used as control. Data represent the mean \pm SEM, $n=3-4$. (E) ATM (KU60019) or ATR (VE-821) inhibitor decreases abundance of p-AKT in U2OS cells. U2OS cells were treated with indicated concentration of KU60019 or VE-821 for 24 h. (F) The expression of wt-p53, but not mutant p53 (p53s269e) defective of transcription activity, increases the level of p-AKT. (G) PFTa,an inhibitor of p53 transcription activity, suppresses the phosphorylation of AKT. U2OS cells were treated with indicated concentration of PFTa for $24 \mathrm{~h}$. 